\title{
IP LIVE PRODUCTION: STATUS, EVOLUTION AND BEST PRACTICES
}

\author{
Chair: José Antônio de Souza Garcia - EBC - Empresa Brasil de Comunicação / SET \\ How can television engineering chart a way for the transition from the current SDI technology towards the \\ future of the workflow fully with IP technology? What are the current offers, best practices and next steps in \\ this evolution?
}

- THE FUTURE OF BROADCAST FACILITIES: THE MIGRATION FROM SDI TO IT INFRASTRUCTURE ("ALL IP") Speaker: Matthew Goldman - Senior Vice President Technology at Ericsson I Fellow \& President of SMPTE / Senior Member at IEEE

In order to become more agile in operations and leverage the economies of scale and flexibility that IT infrastructure brings, Broadcasters must consider migrating from broadcast-specific architectures to IT-based solutions. This goes hand-in-hand with the trend toward software-defined media processing and network function virtualization. This presentation will first give an overview of the challenges that Broadcasters face and the benefits of transforming to "All IP". It then will describe the major standards efforts behind "All IP", including the new SMPTE ST 2110 suite of standards for Professional Media over IP. The current state of the industry will be reviewed and what's to be done next.

- MERITS AND TECHNICAL CHALLENGES LEARNED FROM REAL WORLD IP DEPLOYMENTS

\section{Speaker: Robert Erickson - IP Evangelist - Grass Valley}

The initial IP workflows incorporated proprietary technologies, including non-standardized media transport layers, vendor specific physical routing technologies and media flows orchestrated through a closed ecosystem. But AIMS developed a path to open standards that included multiple vendors designing systems using COTS-based solutions. Large deployments of IP has pushed the envelope on what can currently be deployed by a COTS infrastructure, and what challenges have arisen as this system has been scaled up to meet the customer's functionality requirements. 


\title{
- IP-BASED REFERENCE ARCHITECTURES FOR PRODUCTION AND
} DISTRIBUTION

\author{
Speaker: Boris Kauffmann, Solutions Architect
}

To provide an in-depth look at open, standards-based IP architectures, discuss joint developments with IP fabric vendors, highlight notable reference sites were IP is already a reality, design best practices from IP early adopters, facility-specific IP considerations.

\section{- HOW TO FACE LIVE PRODUCTION CHANGES IN IP}

\section{Speaker: Antonio Leonel da Luz, Presidente, media and content-dynamics}

This is a moment of changes. The transition from HDTV to 4K, SDR to HDR and SDI to IP has haunted a lot of people. Migration strategies and future growth are popping up along with new standards. Different architectures and workflows are being proposed. New and old players are positioning themselves. What will happen to live production? What does SMPTE 2022/2110 and NDI offer us? How to manage and control this system? Which topology is appropriate? Join us and be prepared..

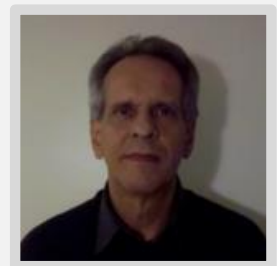

José Antônio de Souza Garcia - EBC - Empresa Brasil de Comunicação / SET

Graduated in 1975 as an Electronics Technician by ETE in Sta. Rita do Sapucaí and in 1982 in Telecommunications Engineering at São Judas University in São Paulo. He has worked in television companies, including TV Tupi-SP, TV Cultura-SP, TV Jovem Pan and currently engineering manager in TV Brasil-SP. Member of SET - Technology Board and SBTVD Forum.

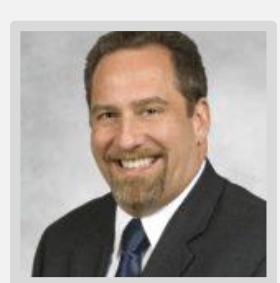

Matthew Goldman - Senior Vice President Technology at Ericsson / Fellow \& President of SMPTE / Senior Member at IEEE

Matthew Goldman is Senior Vice President of Technology, TV \& Media, at Ericsson, where he is focused on video processing and media delivery solutions. He has been actively involved in the development of digital television systems since 1992. He was a prominent participant in the Moving Picture Experts Group where he helped create the MPEG-2 Systems and DSM-CC standards, and he continues to be influential in other industry organizations including the Society of Motion Picture and Television Engineers (SMPTE), the Alliance of IP Media Solutions (AIMS), the Ultra HD Forum, the Digital Video Broadcasting project, the Advanced Television Systems Committee, and the Society of Cable Telecommunications Engineers. Four of his projects have been later recognized by Technology \& Engineering Emmy® Awards. Mr. Goldman received bachelor (high honors) and master of sciences degrees in electrical engineering from Worcester Polytechnic Institute. He holds six patents related to digital video transport. A SMPTE Fellow, he is also a senior member of the IEEE and an inductee of the Academy of Digital Television Pioneers. Mr. Goldman is currently serving as the President of SMPTE. 


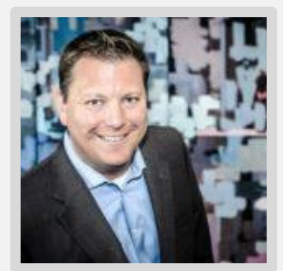

\section{Robert Erickson - IP Evangelist - Grass Valley}

Robert Erickson, currently at GrassValley, with the mission of IP Technology Evangelist. He has worked for 18 years in Television Engineering, has been with KWTV, Sinclair Broadcast Group, Tyler Media and GrassValley since 2008

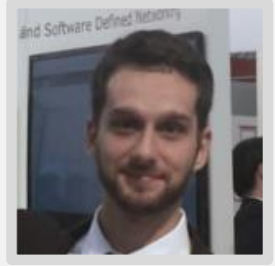

\section{Boris Kauffmann, Solutions Architect}

Solutions Architect at Imagine Communications, more then 10 years working in the audio-visual industry with film, broadcast, post-production equipment and cutting edge technologies, have developed extensive knowledge on sound and image acquisition, processing, encoding, transcoding and transport over SDI/IP infrastructures, vast experience integrating and implementing solutions from different manufacturers. Have conducted proof of concepts and technical presentations for broadcasters and telecommunication all over the country.

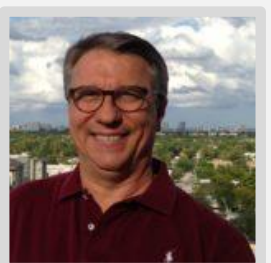

\section{Antonio Leonel da Luz, Presidente, media and content-dynamics}

Leonel da Luz is the president of media and content-dynamics that serves the Brazilian and Latin American market, offering consulting, projects, products and professional services. With masters degree in engineering and business management studying at Mauá-IMT, INATEL, FGV and MIT, Leonel has accumulated success stories in several national and international companies, such as TV Cultura-SP, Ampex, Philips, TV Anhanguera, Harris and Grass Valley, among others. 